\title{
Comparative Study of the Reaction Kinetics of Three Residual Biomasses
}

\author{
Arnaldo Martinez, ${ }^{\mathrm{a}}$ Lourdes Meriño, ${ }^{\mathrm{a}, *}$ Alberto Albis, ${ }^{\mathrm{b}}$ and Jorge Ortega ${ }^{\mathrm{a}}$ \\ Kinetic analysis for the combustion of three agro-industrial biomass \\ residues (coconut husk, corn husk, and rice husk) was carried out in order \\ to provide information for the generation of energy from them. The analysis \\ was performed using the results of the data obtained by thermogravimetric \\ analysis (TGA) at three heating rates $(10,20$, and $30 \mathrm{~K} / \mathrm{min})$. The biomass \\ residues were characterized in terms of proximate analysis, elemental \\ analysis, calorific value, lignin content, $\alpha$-cellulose content, hemicellulose \\ content, and holocellulose content. The biomass fuels were thermally \\ degraded in an oxidative atmosphere. The results showed that the \\ biomass thermal degradation process is comprised of the combustion of \\ hemicellulose, cellulose, and lignin. The kinetic parameters of the \\ distributed activation energy model indicated that the activation energy \\ distribution for the pseudocomponents follows lignin, cellulose, and \\ hemicellulose in descending order. The activation energy values for each \\ set of reactions are similar between the heating rates, which suggests that \\ it is independent of the heating rate between $10 \mathrm{~K} / \mathrm{min}$ and $30 \mathrm{~K} / \mathrm{min}$. For \\ all the biomass samples, the increased heating rate resulted in the overlap \\ of the hemicellulose and cellulose degradation events.
}

Keywords: Biomass; Combustion; Kinetic parameters; DAEM

Contact information: a: Agroindustrial program, Faculty of Engineering, Universidad del Atlántico, Km. 7 Vía a Puerto Colombia, Atlántico, Colombia; b: Chemical Engineering Program, Faculty of Engineering, Universidad del Atlántico, Km. 7 Vía a Puerto Colombia, Atlático, Colombia;

* Corresponding author: lourdesmerino@mail.uniatlantico.edu.co

\section{INTRODUCTION}

The shortage of conventional fossil fuels and the environmental problems that arise from their use, such as global warming and acid rain, have become a cause of concern for their contribution to climate change. Biomass is an alternative renewable and clean energy resource that can alleviate pollution problems, so it has received increasing attention from researchers (Demirbaş 2001; Yaman 2004). There are many conversion technologies to utilize biomass, such as direct combustion, gasification, pyrolysis, flash pyrolysis, and anaerobic digestion, among others (Song et al. 2004).

In the literature, the combustion characteristics of different biomasses have been studied primarily through thermogravimetric analysis (TGA) (Kok and Ozgur 2017; Mlonka-Mędrala et al. 2019). Thermogravimetric analysis has been used to identify different polymeric lignocellulosic fractions present in biomass residues and to determine the reactivities of carbonized residues in presence of reactive atmospheres (Wilk et al. 2019; Sher et al. 2020). The kinetic study is considered an important criterion for the measurement of the reactivity potentials of coals and biomass residues that are used as fuels. The distributed activation energy model (DAEM) has been widely used to describe the thermal degradation of different biomasses (Hu et al. 2016; Oliveros et al. 2019) and 
to obtain precise kinetic parameters such as the apparent activation energy $(E)$ and the other thermodynamic parameters calculated from $E$, including the pre-exponential factor $(A)$.

In this sense, agrobusinesses constitute an important line of the Colombian economy, since they add value to the products of the field. One of the peculiarities of this line of the economy is the large amount of biomass produced as a by-product during the transformation of the raw material; In some cases, the amount of waste generated during harvesting and processing can be as high as $50 \%$ of the tons produced, such as corn, coconut, and rice husk waste. These wastes, as they do not receive adequate treatment, end up in rivers and streams, or in garbage dumps and sewers in cities, causing serious environmental and solid waste management problems.

Although they are currently considered waste, they have a high potential due to their composition. Some potential uses are being studied so that they can become an important source of energy or fuel if used properly.

The objective of this study was to estimate the kinetic behavior of the combustion of rice husk, coconut husk, and corn husk by the DAEM, from the thermogravimetric curves obtained using a TG analyzer under three heating rates (10, 20, and $30 \mathrm{~K} / \mathrm{min})$. The results associated with this type of study are of great importance, since they provide information that can be used for the kinetic modeling of the combustion process for the generation of energy from biomass.

\section{EXPERIMENTAL}

\section{Methods}

Figure 1 outlines the general methodology of this work.

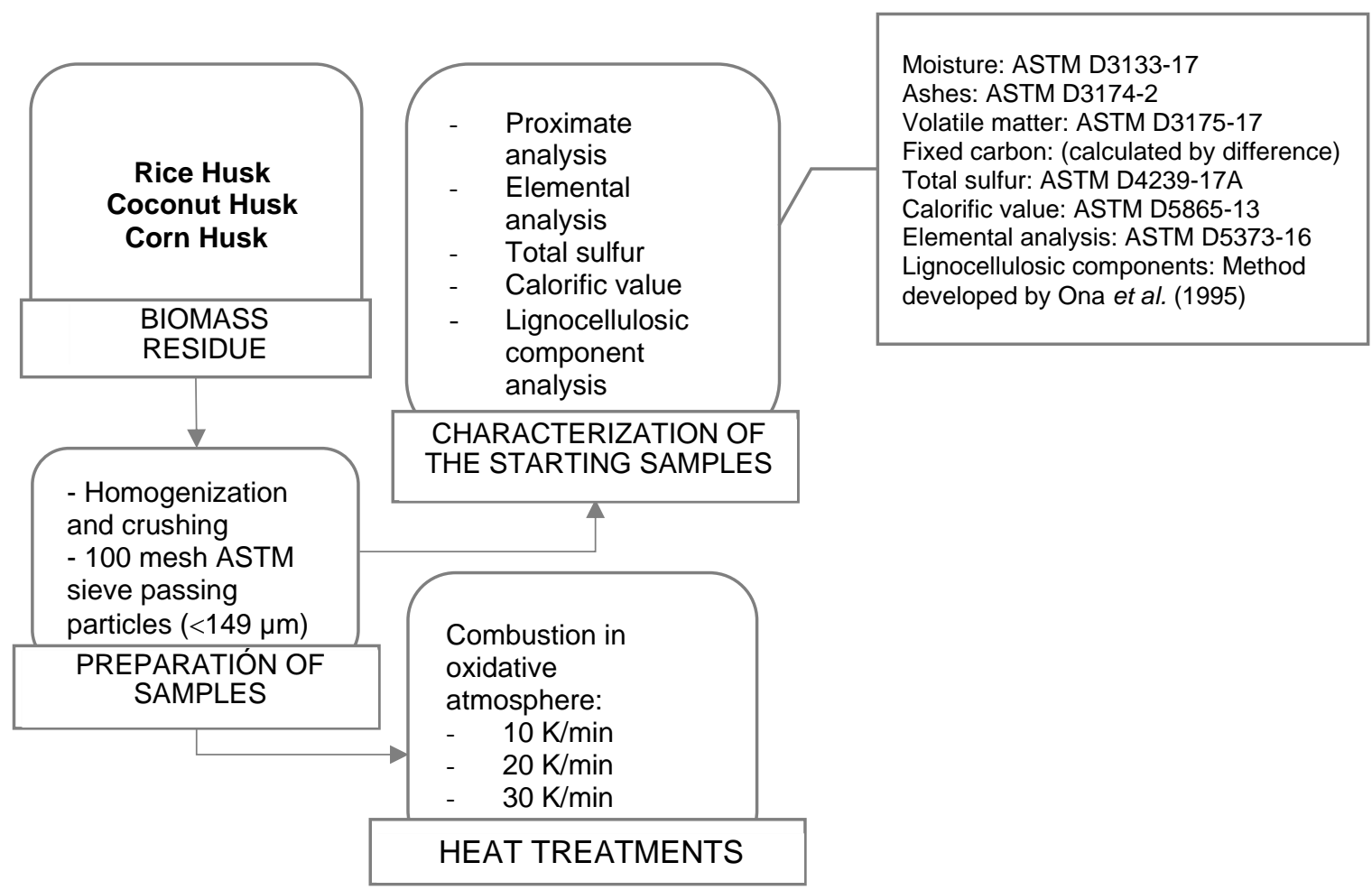

Fig. 1. Methodology 
Figure 2.

The stages in which the methodology was divided to be carried out are shown in

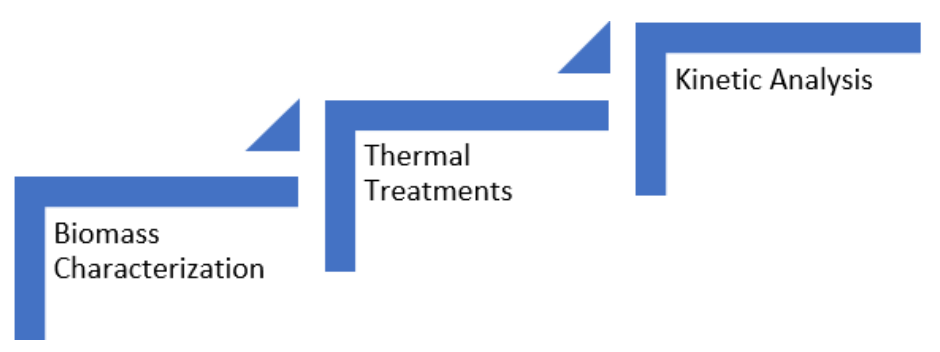

Fig. 2. Stages of methodology

\section{Biomass Characterization}

Three industrial-waste biomass samples were selected for this study: rice husks, coconut husk, and corn husks, all of which were obtained from Atlántico, Colombia. In the proximate analysis, total humidity, the ash content, and the volatile matter were determined using the ASTM standards D-3173 (2017), D-3174 (2002), and D-3175 (2017), respectively. The fixed carbon (by difference) was also calculated. The elemental analysis quantified the content of the carbon, hydrogen, nitrogen, and oxygen using the ASTM standard D-5373 (2016). The total sulfur was calculated according to the ASTM standard D-4239, method A (2017) and the calorific value was determined according to the ASTM standard D-5865 (2013).

The major component analysis determined the percentage of cellulose, hemicellulose, lignin, and extractives according to the method developed by Ona et al. (1995). Figure 3 presents images of the biomass characterization.

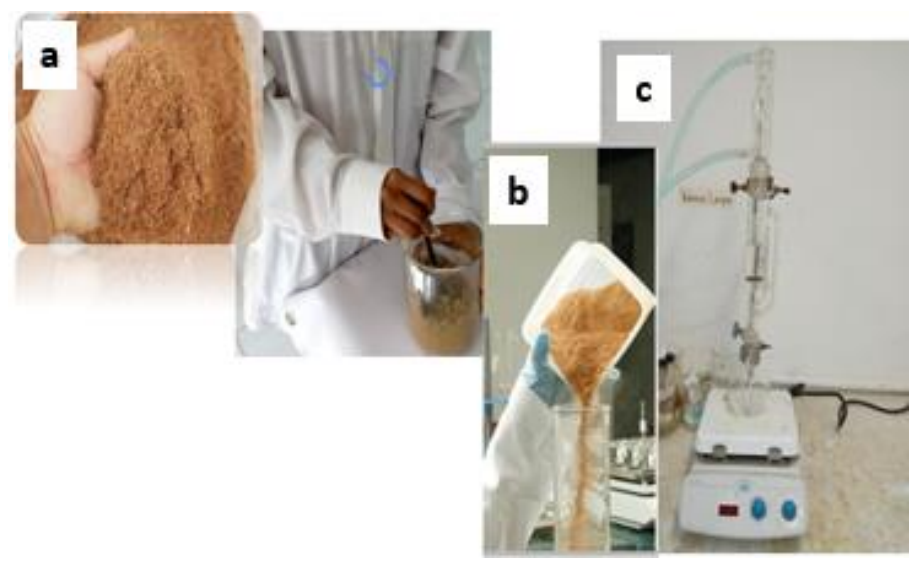

Fig. 3. Biomass characterization (a) preparation of samples, homogenization and crushing process (b) sieve passing particles $(<149 \mu \mathrm{m})$ (c) disposition of the equipment to carry out the lignocellulosic components analysis

\section{Thermal Treatments}

Biomass fuels were thermally degraded in an oxidative atmosphere using a SETSYS Evolution TGA-DTA/DSC thermal analyzer (Setaram, Caluire-et-Cuire, France) in the TG mode (Fig. 4). Ten to $20 \mathrm{mg}$ of sample with a particle size less than $150 \mu \mathrm{m}$ were placed to ensure complete combustion (Ninduangdee and Kuprianov 2014; MlonkaMędrala et al. 2019) in an alumina sample holder. Synthetic air was used as stripping gas 
with a flow of $30 \mathrm{~mL} / \mathrm{min}$ and three heating rates $(10,20$, and $30 \mathrm{~K} / \mathrm{min})$ were evaluated in a temperature range between ambient temperature (approximately $298 \mathrm{~K}$ ) and $1273 \mathrm{~K}$.

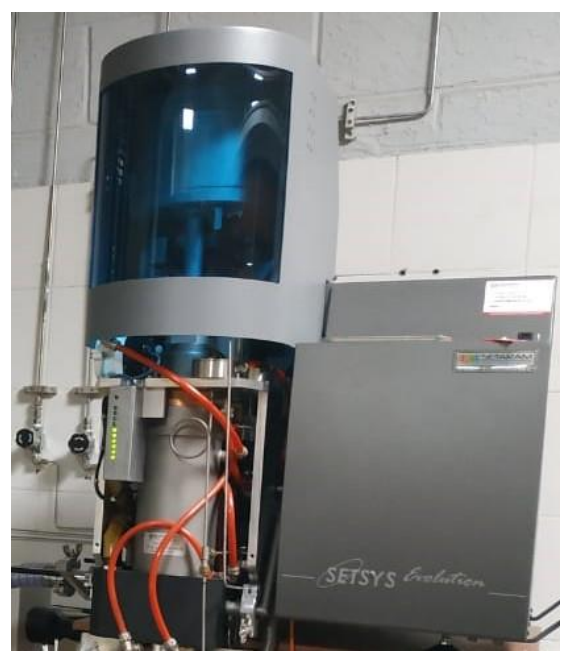

Fig. 4. SETSYS Evolution TGA-DTA/DSC

\section{Kinetic Analysis Using the DAEM}

The DAEM has been used successfully to describe the thermal degradation of various solid materials (Várhegyi et al. 2002; Hu et al. 2016; Oliveros et al. 2019). Whether in an inert or oxidative atmosphere, the entire process of thermal degradation consists of a series of irreversible reactions of the first order occurring successively.

In this model, the first derivative of a thermogravimetric curve (DTG) is calculated according to Eq. 1,

$$
Y^{\text {Calc }}(t)=-\sum_{j=1}^{M} c_{j} d x_{j} / d t
$$

where $x_{j}$ is the unreacted fraction of the material, represented by the kinetic equation of order $j, c_{j}$ represents the contribution of the $j$-th partial reaction of the measured quantity, and $M$ corresponds to the number of pseudo-components or the set of reactions that can be described through the same probability distribution function. The model assumes a firstorder kinetic model and an Arrhenius dependency for the kinetic constant.

Oxidative degradation for hemicellulose and cellulose occurs at lower temperatures compared to lignin, given that their structures are amorphous, random, and more "soft"; these differences in their chemical structures lead to different reactivities (Ren et al. 2018; Carrier et al 2011), and therefore, the activation energy required to carry out the combustion of these organic polymers is lower. This means that the activation energy values increase in the order of hemicellulose, cellulose and finally lignin.

The activation energies for the reactions involved are distributed on a Gaussian distribution function with parameters $E_{0 j}$ and $\sigma_{j}$. If the solution of a first-order kinetic equation with a given value $E$ is denoted as $X_{j}(t, E)$, the functions $x_{j}$ from Eq. 1 are calculated according to Eq. 2,

$$
x_{j}(t)=\int_{0}^{\infty}(2 \pi)^{-1 / 2} \sigma j^{-1} \exp \left[\frac{-\left(E-E_{0, j}\right)^{2}}{2 \sigma_{j}^{2}}\right] X j(t, E) d E
$$

To evaluate the integral corresponding to Eq. 2, a change is made in the lower limit of integration from 0 to $-\infty$ without affecting the results and subsequently the Gauss- 
Hermite quadrature rule is used to approximate this new integral, as shown in Eq. 3 and Eq. 4 (Bhavanam and Sastry 2015),

$$
\begin{aligned}
& \mu_{j}=\frac{2\left(E-E_{0, j}\right)}{\sqrt{2} \sigma_{j}} \\
& x_{j}(t) \cong \frac{1}{2 \pi}^{-1 / 2} \sum_{i=1}^{N} w_{i} \exp \left(0.72 \mu_{i j}^{2}\right) X j\left(t, \mu_{i j}\right)
\end{aligned}
$$

where $w_{i}, y$, and $\mu_{i j}$ are the mass and abscissa factors of the Gauss-Hermite quadrature formula. In this equation, the results of the optimization of change of scale proposed by Donskoi and McElwain (2000) and a value of $\mathrm{N}$ equal to 80, as suggested by Várhegyi et al. (2002), are used. The adjustment was made with a non-linear least squares method, minimizing the sum presented by Várhegyi et al. (2002; 2007) in Eq. 5,

$$
S=\sum_{k=1}^{N_{\exp }} \sum_{i=1}^{N_{k}} \frac{\left[Y_{k}^{o b s}\left(t_{i}\right)-Y_{k}^{c a l}\left(t_{i}\right)\right]^{2}}{\left(N_{k}^{\max }\left(Y_{k}^{o b s}\right)^{2}\right.}
$$

For each experimental curve, the fit obtained is characterized by Eq. 6,

$$
f i t(\%)=100 \frac{\left[\left[Y_{k}^{o b s}\left(t_{i}\right)-Y_{k}^{c a l}\left(t_{i}\right)\right]^{2}\right]^{1 / 2}}{\left(N_{k}^{\text {max }}\left(Y_{k}^{o b s}\right)^{2}\right.}
$$

The previous equations were solved with the help of an algorithm designed by Oliveros et al. (2019) in MATLAB ${ }^{\circledR}$ software (MathWorks, Natick, MA) using the optimization functions and built-in ODE solvers.

\section{RESULTS AND DISCUSSION}

\section{Biomass Characterization}

Following the results of the proximate, the elemental analysis and component analysis performed on the samples are presented as described in the methodology and consolidated in Tables 1, 2, and 3.

Table 1. Results of the Proximate Analysis

\begin{tabular}{|c|c|c|c|}
\hline \multicolumn{4}{|c|}{ Proximate Analysis (\%) Mass, Dry Basis } \\
\hline & Rice Husk & Coconut Husk & Corn Husk \\
\hline Moisture & 8.61 & 8.83 & 4.62 \\
\hline Ash & 22.37 & 0.49 & 3.87 \\
\hline Volatile Matter & 72.69 & 92.16 & 83.78 \\
\hline Fixed Carbon & 4.94 & 7.35 & 12.35 \\
\hline Sulphur & 0.05 & 0.03 & 0.10 \\
\hline Calorific value (MJ/Kg) & 15.31 & 24.29 & 20.56 \\
\hline
\end{tabular}

Table 2. Results of the Elemental Analysis

\begin{tabular}{|c|c|c|c|}
\hline \multicolumn{4}{|c|}{ Elemental Analysis (\%) Mass, Dry Basis } \\
\hline Rice Husk & Coconut Husk & Corn Husk \\
\hline Carbon & 34.60 & 47.7 & 42.30 \\
\hline Hydrogen & 4.28 & 5.44 & 5.87 \\
\hline Nitrogen & 0.30 & 0.06 & 0.46 \\
\hline Oxygen & 38.37 & 46.25 & 47.31 \\
\hline
\end{tabular}


Table 3. Results of the Component Analysis of Biomass Samples

\begin{tabular}{|c|c|c|c|}
\hline \multicolumn{5}{|c|}{ Component Analysis (\%) Mass } \\
\hline & Rice Husk & Coconut Husk & Corn Husk \\
\hline Lignin & 19.58 & 12.34 & 5.36 \\
\hline Holocellulose & 62.39 & 74.812 & 63.66 \\
\hline Alpha-cellulose & 60.323 & 74.45 & 1.70 \\
\hline Hemicellulose & 2.06 & 0.366 & 61.96 \\
\hline Extractive & 2.35 & 2.64 & 13.96 \\
\hline
\end{tabular}

The results obtained from the elemental analysis and the calorific value values shown in Table 2 are typical for these types of samples and are related to those reported in the literature. The calorific value reported by other researchers for rice husk is between 16.35 and $16.44 \mathrm{MJ} / \mathrm{kg}$, for coconut husk it is between 18.23 and $20.01 \mathrm{MJ} / \mathrm{kg}$, and for corn residues it is between 17.96 and $18.41 \mathrm{MJ} / \mathrm{kg}$ (Rambo et al. 2015; Marafon et al. 2019).

It was also observed that a higher ash content decreased the energy density of the biomass (Raveendran and Gasnesh 1996). For example, the rice husk had the highest ash percentage $(22.37 \%)$ and the lowest power calorific value $(15.31 \mathrm{MJ} / \mathrm{kg})$, followed by the corn husk and coconut husk biomasses.

Regarding the results obtained from the chemical composition of the lignocellulosic materials, holocellulose was found to be present as the predominant composition in most of these materials (Xiao et al. 2001; Halim et al. 2016). According to the result presented in Table 3, the holocellulose content in all the biomass samples comprised more than half of the total solid composition, which shows that cellulose and hemicellulose are the main components of the biomasses under study.

\section{Kinetics Analysis using the DAEM}

The experimental data obtained from TGA of the biomass samples was satisfactorily modeled with the three Gaussian functions. This was done under the assumption that during the combustion process, the decomposition of the three main components - hemicellulose, cellulose, and lignin, occurs (Carrier et al. 2011; Kok and Ozgur 2017). In general, the three components simultaneously are not clearly defined as independent events, but they appear on the DTG curves as two events in which the phenomena coexist. The temperature range evaluated with the DAEM was 453 to $833 \mathrm{~K}$, in which the event of moisture release was excluded.

The distributed activation energy model (DAEM) has been used successfully to describe thermal degradation of various solid materials (Santander et al. 2019). Whether in an inert or oxidative atmosphere, the entire thermal degradation process consists of a series of irreversible first-order reactions occurring in succession and an Arrhenius dependence for the kinetic constant. The activation energies for the reactions involved are considered distributed in a Gaussian distribution function with parameters $E_{0, \mathrm{j}}$ and $\sigma_{\mathrm{j}}$. (Ren et al. 2018). Reaction kinetic parameters are derived from various TGA curves that are typically obtained for experiments at low constant heating rate.

The kinetic reaction parameters were determined from the TG curves that were obtained from the heat treatments at the heating rates of 10, 20, and $30 \mathrm{~K} / \mathrm{min}$. Figures 5, 6 , and 7 illustrate the fit obtained with three sets of the DAEM reactions the rice husk, coconut husk, and corn husk samples, respectively, at different heating rates. The first peak observed in the profiles of the different biomasses corresponds to the most reactive fraction (hemicellulose), which rapidly degraded at relatively low temperatures ( $453 \mathrm{~K}$ to $623 \mathrm{~K}$ ), 
with the release of volatiles that were oxidized in an air atmosphere and was largely responsible for the generation of combustion gases (Flores and Quiñones 2018). When the temperature increased, the next less soft fraction, attributed to cellulose, was thermally degraded in the temperature range of $548 \mathrm{~K}$ to $623 \mathrm{~K}$. Lignin was the most difficult to oxidize fraction, which had a higher temperature range (523 K to $773 \mathrm{~K}$ ) (Lozano 2009; Flores and Quiñones 2018).

The curve fitting obtained by the DAEM for the rice husk samples shown in Fig. 5 is presented with a dotted line, while the experimental data is shown as a continuous line. The curves referring to each reaction set were represented by the hemicellulose, cellulose, and lignin components of the biomass, which are represented the red, blue, and green dotted lines, respectively. It is possible to observe a good fit of the model to the experimental data at the different heating rates.

As can be seen in Fig. 5, as the heating rate increased, the combustion of the hemicellulose was favored because the conversion rate increased. The cellulose behaved in the same way. However, when comparing the cellulose with the lignin, it was evident that at $30 \mathrm{~K} / \mathrm{min}$, the value of $\mathrm{d} \alpha / \mathrm{d} t$ for lignin was lower. This is corroborated when comparing the values of the kinetic parameters obtained by the DAEM, which are shown

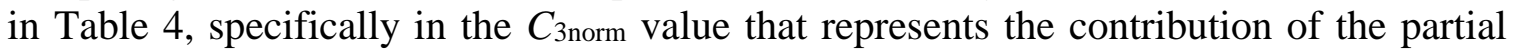
reaction of lignin to the measured quantity (Várhegyi et al. 2002). In this instance, a heating rate of $30 \mathrm{~K} / \mathrm{min}$ had a value of 0.13 . For the heating rates of $10 \mathrm{~K} / \mathrm{min}$ and $20 \mathrm{~K} / \mathrm{min}$, the values were 0.212 and 0.254 , respectively.
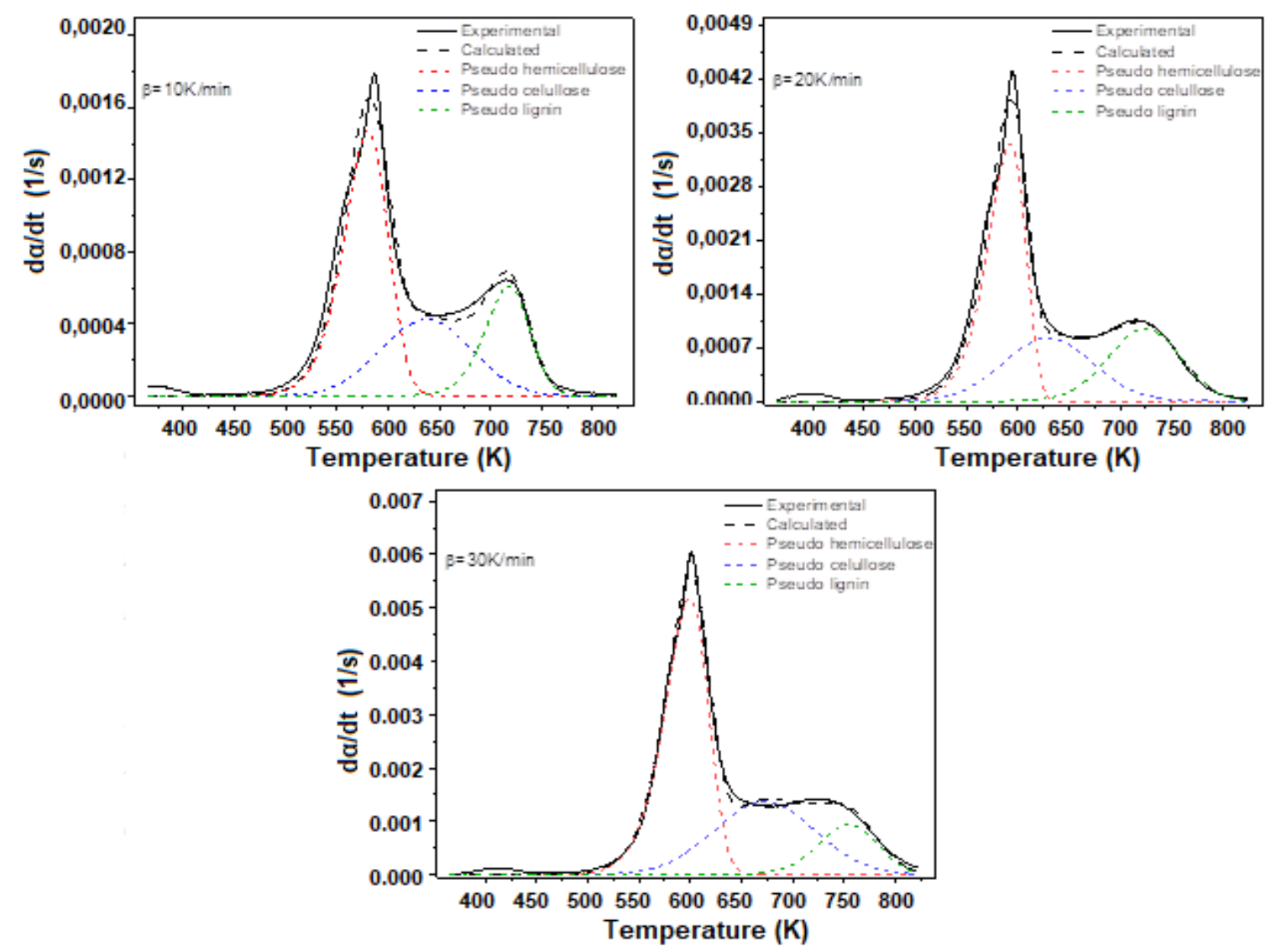

Fig. 5. Fit DAEM to DTG data from the rice husk biomass samples during combustion at different heating rates 
Table 4 presents the parameters calculated using this algorithm, where the first activation energy $\left(E_{01}\right)$ and the first pre-exponential factor $\left(A_{1}\right)$ will probably correspond to the decomposition of the hemicellulose, while the second parameters $\left(E_{02}, A_{2}\right)$ will correspond to the decomposition of the cellulose. For lignin, the activation energy and the pre-exponential factor parameters will correspond to those denoted as $E_{03}$ and $A_{3}$.

In general, the activation energy required in the combustion of the rice husk samples at different heating rates presented similar values. The activation energy was between 153 and $156 \mathrm{~kJ} / \mathrm{mol}$ for the first set of reactions, between 185 and $192 \mathrm{~kJ} / \mathrm{mol}$ for the second set of reactions, and between 261 and $270 \mathrm{~kJ} / \mathrm{mol}$ for the third set of reactions. This suggests that the activation energy is independent of the heating rate between 10 and $30 \mathrm{~K} / \mathrm{min}$.

Table 4. Kinetic Parameters of the Rice Husk Obtained by DAEM

\begin{tabular}{|c|c|c|c|}
\hline Parameters & Rice 10 (K/min) & Rice 20 (K/min) & Rice 30 (K/min) \\
\hline $\boldsymbol{C}_{\text {1norm }}$ & $4.98 \mathrm{E}-01$ & $4.76 \mathrm{E}-01$ & $5.37 \mathrm{E}-01$ \\
\hline $\boldsymbol{A}_{\mathbf{1}}(\mathbf{1} / \mathbf{s})$ & $5.33 \mathrm{E}+11$ & $1.05 \mathrm{E}+12$ & $5.61 \mathrm{E}+11$ \\
\hline $\boldsymbol{E}_{01}(\mathbf{k J} / \mathbf{m o l})$ & $1.54 \mathrm{E}+02$ & $1.56 \mathrm{E}+02$ & $1.53 \mathrm{E}+02$ \\
\hline $\boldsymbol{\sigma}_{01}(\mathbf{k J} / \mathbf{m o l})$ & 6.16 & $7.28 \mathrm{E}-03$ & 4.18 \\
\hline $\boldsymbol{C}_{\mathbf{2 n o r m}}$ & $2.90 \mathrm{E}-01$ & $2.70 \mathrm{E}-01$ & $3.27 \mathrm{E}-01$ \\
\hline $\boldsymbol{A}_{\mathbf{2}}(\mathbf{1} / \mathbf{s})$ & $9.54 \mathrm{E}+12$ & $1.00 \mathrm{E}+14$ & $5.52 \mathrm{E}+12$ \\
\hline $\boldsymbol{E}_{\mathbf{0 2}}(\mathbf{k J} / \mathbf{m o l})$ & $1.85 \mathrm{E}+02$ & $1.92 \mathrm{E}+02$ & $1.87 \mathrm{E}+02$ \\
\hline $\boldsymbol{\sigma}_{02}(\mathbf{k J} / \mathbf{m o l})$ & $2.36 \mathrm{E}+01$ & $2.45 \mathrm{E}+01$ & $2.53 \mathrm{E}+01$ \\
\hline $\boldsymbol{C}_{3 \text { norm }}$ & $2.12 \mathrm{E}-01$ & $2.54 \mathrm{E}-01$ & $1.35 \mathrm{E}-01$ \\
\hline $\boldsymbol{A}_{\mathbf{3}}(\mathbf{1} / \mathbf{s})$ & $4.13 \mathrm{E}+17$ & $1.06 \mathrm{E}+17$ & $5.89 \mathrm{E}+16$ \\
\hline $\boldsymbol{E}_{03}(\mathbf{k J} / \mathbf{m o l})$ & $2.71 \mathrm{E}+02$ & $2.62 \mathrm{E}+02$ & $2.67 \mathrm{E}+02$ \\
\hline $\boldsymbol{\sigma}_{03}(\mathbf{k J} / \mathbf{m o l})$ & $1.10 \mathrm{E}+01$ & $2.24 \mathrm{E}+01$ & $1.58 \mathrm{E}+01$ \\
\hline
\end{tabular}
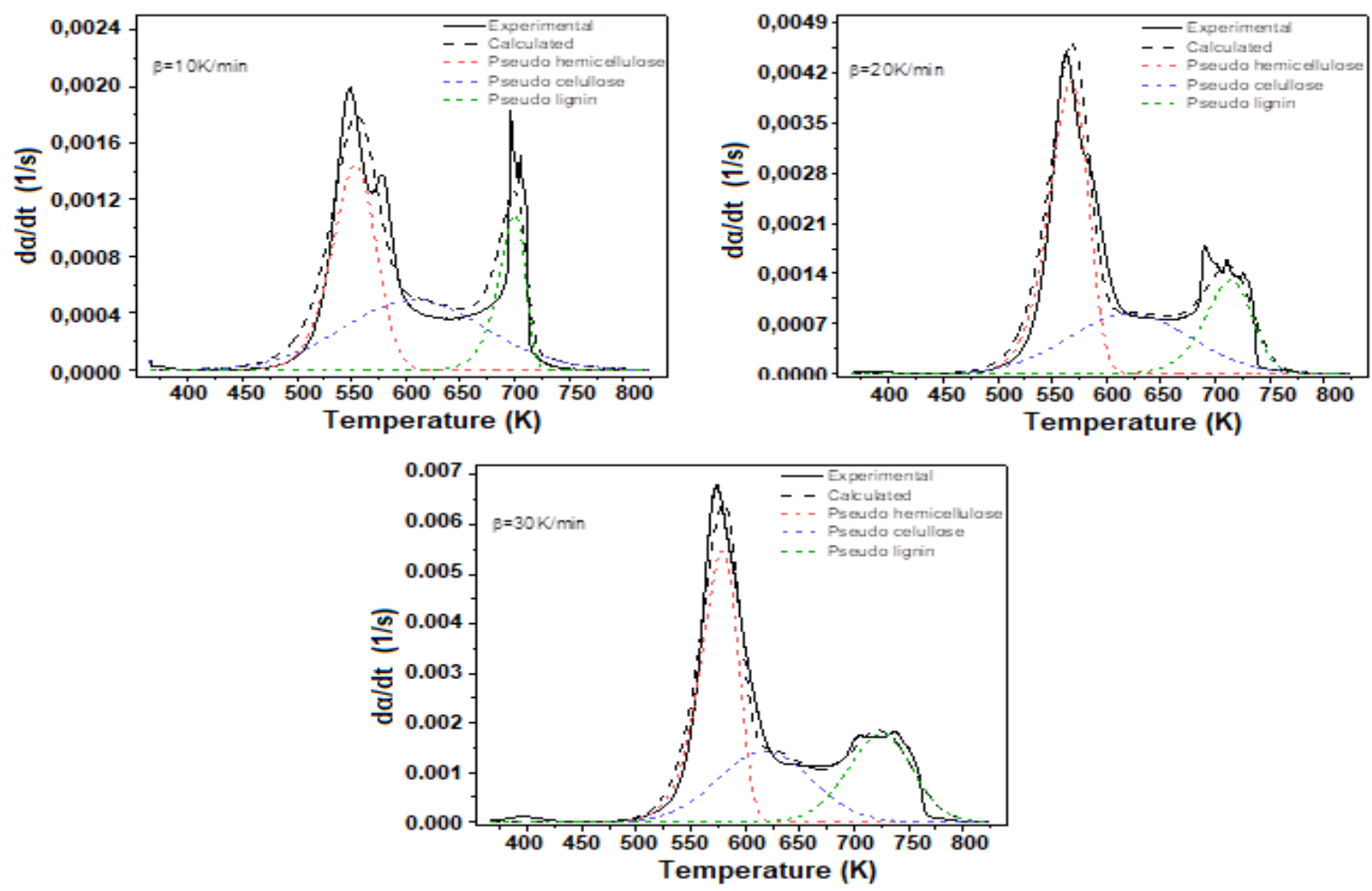

Fig. 6. Fit of the DAEM to DTG data from the coconut husk biomass samples during combustion at different heating rates 
Similar to the rice husk samples, as the $\beta$ of the coconut husk samples increased, the decomposition reaction of the hemicellulose was favored since the value of the conversion rate increased. However, this parameter decreased for the cellulose as the decomposition rate of the lignin increased. Both effects can be seen in Fig. 6, and the results are further corroborated with the values of $C_{1 \text { norm }}, C_{2 \text { norm, }}$ and $C_{3 \text { norm }}$ in Table 5.

Table 5. Kinetic Parameters of the Coconut Husk Obtained by DAEM

\begin{tabular}{|c|c|c|c|}
\hline Parameters & Coconut $10(\mathrm{~K} / \mathrm{min})$ & Coconut $20(\mathrm{~K} / \mathrm{min})$ & Coconut $30(\mathrm{~K} / \mathrm{min})$ \\
\hline $\mathbf{C}_{1 \text { norm }}$ & 3.91E-01 & 4.92E-01 & $4.55 \mathrm{E}-01$ \\
\hline$A_{1}(1 / s)$ & $6.311 \mathrm{E}+13$ & $7.59 \mathrm{E}+13$ & $5.75 \mathrm{E}+13$ \\
\hline $\mathrm{E}_{01}(\mathrm{~kJ} / \mathrm{mol})$ & $1.68 \mathrm{E}+02$ & $1.69 \mathrm{E}+02$ & $1.69 \mathrm{E}+02$ \\
\hline$\sigma_{01}(\mathrm{~kJ} / \mathrm{mol})$ & 7.90 & 4.72 & 2.83 \\
\hline $\mathbf{C}_{2 \text { norm }}$ & $4.22 \mathrm{E}-01$ & $3.11 \mathrm{E}-01$ & $2.90 \mathrm{E}-01$ \\
\hline$A_{2}(1 / s)$ & $8.44 \mathrm{E}+13$ & $6.77 E+13$ & $4.19 \mathrm{E}+13$ \\
\hline$E_{02}(\mathrm{~kJ} / \mathrm{mol})$ & $1.88 \mathrm{E}+02$ & $1.87 \mathrm{E}+02$ & $1.81 \mathrm{E}+02$ \\
\hline$\sigma_{02}(\mathrm{~kJ} / \mathrm{mol})$ & $3.94 \mathrm{E}+01$ & $3.25 E+01$ & $2.30 \mathrm{E}+01$ \\
\hline $\mathbf{C}_{3 \text { 3norm }}$ & $1.87 \mathrm{E}-01$ & 1.97E-01 & $2.56 \mathrm{E}-01$ \\
\hline$A_{3}(1 / s)$ & $9.96 \mathrm{E}+22$ & $1.73 \mathrm{E}+16$ & $7.56 \mathrm{E}+16$ \\
\hline$E_{03}(\mathrm{~kJ} / \mathrm{mol})$ & $3.33 \mathrm{E}+02$ & $2.46 \mathrm{E}+02$ & $2.57 \mathrm{E}+02$ \\
\hline$\sigma_{03}(\mathrm{~kJ} / \mathrm{mol})$ & $6.47 \mathrm{E}-01$ & $8.77 E+00$ & $1.70 \mathrm{E}+01$ \\
\hline
\end{tabular}
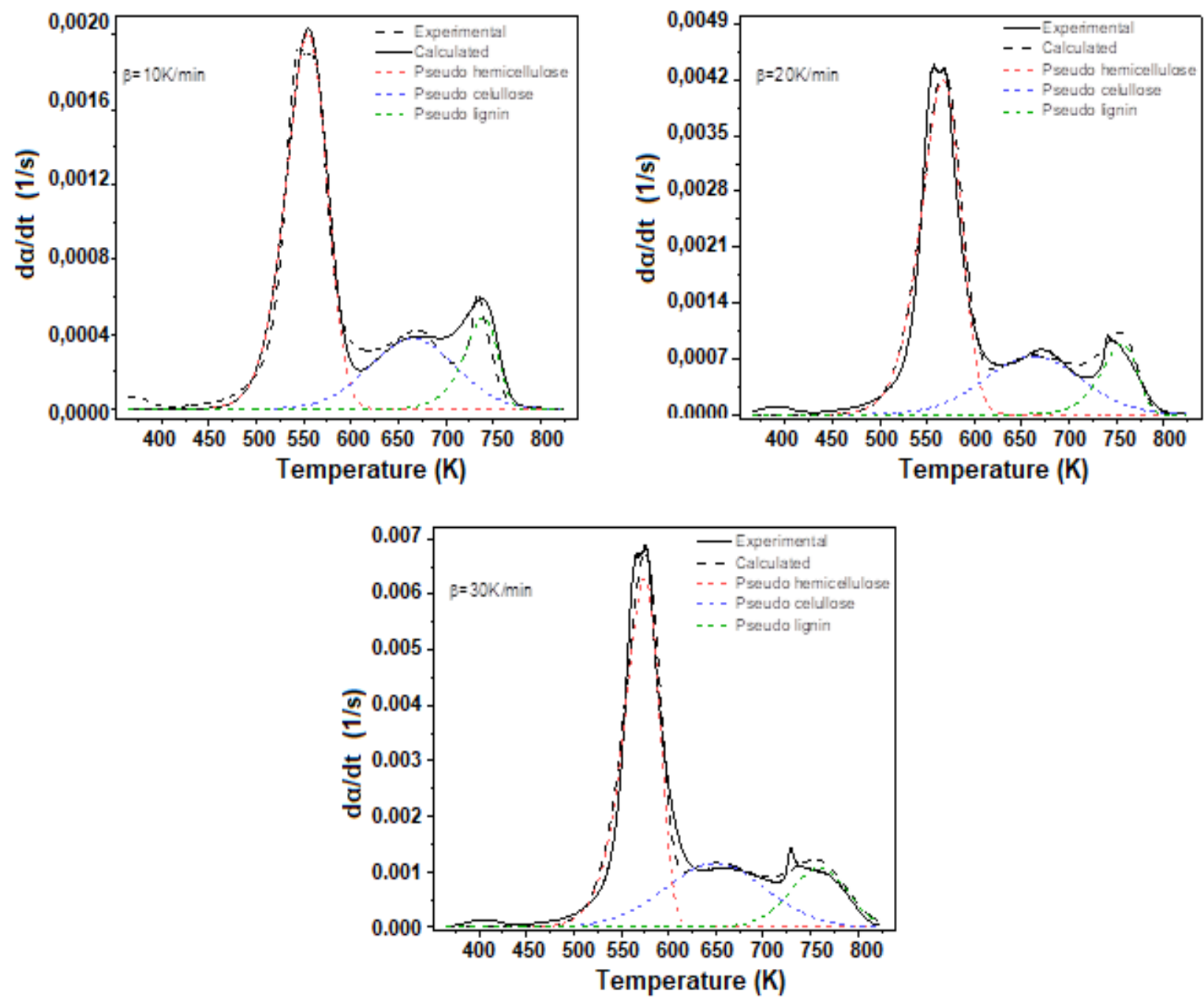

Fig. 7. Fit of the DAEM to DTG data from the corn husk biomass samples during combustion 
The activation energy required in the combustion of the coconut husk biomass at different $\beta$-values presented similar values. The activation energy was approximately 169 $\mathrm{kJ} / \mathrm{mol}$ for the first set of reactions, between 181 and $188 \mathrm{~kJ} / \mathrm{mol}$ for the second set of reactions, and between 246 and $258 \mathrm{~kJ} / \mathrm{mol}$ for the third set of reactions. For the third set, the smallest adjustment of the data obtained by DAEM to the experimental ones was achieved for the coconut husk sample treated at $10 \mathrm{~K} / \mathrm{min}$. For this sample, the activation energy value of $333 \mathrm{~kJ} / \mathrm{mol}$ was atypical and greater than the activation energy values for the coconut husk at $20 \mathrm{~K} / \mathrm{min}$ and $30 \mathrm{~K} / \mathrm{min}$ (Fig. 6).

In the case of the corn husk biomass (Fig. 7), the thermal behavior of the samples was similar to the rice husk and coconut husk biomass samples. It is possible to see an increased in the conversion speed $(\mathrm{d} \alpha / \mathrm{d} t)$ of hemicellulose in the corn husk biomass as the $\beta$-value increased. Conversely, the contribution of the volatiles decreased as a result of the hemicellulose degradation denoted as $C_{1}$ norm in Table 6.

Table 6. Kinetic Parameters of the Corn Husk Obtained by DAEM

\begin{tabular}{|c|c|c|c|}
\hline Parameters & Corn 10 (K/min) & Corn 20 (K/min) & Corn 30 (K/min) \\
\hline $\boldsymbol{C}_{\text {1norm }}$ & $6.25 \mathrm{E}-01$ & $6.15 \mathrm{E}-01$ & $5.56 \mathrm{E}-01$ \\
\hline $\boldsymbol{A}_{\mathbf{1}}(\mathbf{1} / \mathbf{s})$ & $6.73 \mathrm{E}+11$ & $7.47 \mathrm{E}+11$ & $2.32 \mathrm{E}+12$ \\
\hline $\boldsymbol{E}_{\mathbf{0 1}}(\mathbf{k J} / \mathbf{m o l})$ & $1.48 \mathrm{E}+02$ & $1.48 \mathrm{E}+02$ & $1.53 \mathrm{E}+02$ \\
\hline $\boldsymbol{\sigma}_{\mathbf{0 1}}(\mathbf{k J} / \mathbf{m o l})$ & 6.84 & 5.72 & 2.56 \\
\hline $\boldsymbol{C}_{\mathbf{2 n o r m}}$ & $2.47 \mathrm{E}-01$ & $2.63 \mathrm{E}-01$ & $2.89 \mathrm{E}-01$ \\
\hline $\boldsymbol{A}_{\mathbf{2}}(\mathbf{1} / \mathbf{s})$ & $2.03 \mathrm{E}+13$ & $1.06 \mathrm{E}+13$ & $6.86 \mathrm{E}+13$ \\
\hline $\boldsymbol{E}_{\mathbf{0 2}}(\mathbf{k J} / \mathbf{m o l})$ & $1.98 \mathrm{E}+02$ & $1.90 \mathrm{E}+02$ & $1.94 \mathrm{E}+02$ \\
\hline $\boldsymbol{\sigma}_{02}(\mathbf{k J} / \mathbf{m o l})$ & $2.50 \mathrm{E}+01$ & $2.78 \mathrm{E}+01$ & $3.06 \mathrm{E}+01$ \\
\hline $\boldsymbol{C}_{\mathbf{3 n o r m}}$ & $1.29 \mathrm{E}-01$ & $1.22 \mathrm{E}-01$ & $1.55 \mathrm{E}-01$ \\
\hline $\boldsymbol{A}_{\mathbf{3}}(\mathbf{1} / \mathbf{s})$ & $2.46 \mathrm{E}+16$ & $2.32 \mathrm{E}+16$ & $3.95 \mathrm{E}+16$ \\
\hline $\boldsymbol{E}_{\mathbf{0 3}}(\mathbf{k J} / \mathbf{m o l})$ & $2.61 \mathrm{E}+02$ & $2.62 \mathrm{E}+02$ & $2.66 \mathrm{E}+02$ \\
\hline $\boldsymbol{\sigma}_{\mathbf{0 3}}(\mathbf{k J} / \mathbf{m o l})$ & 1.43 & 3.58 & 16.40 \\
\hline
\end{tabular}

When comparing the DTG profiles and the main components for each biomass, the cellulose reaction range of the coconut husk biomass decreased as the $\beta$-value increased, while the reaction zone of the lignin increased. For the corn husk samples, both the cellulose and the lignin reaction ranges increased as the $\beta$-value increased. For the rice husk samples, no trend was observed in the reaction zones of the events. It was generally observed that the increased heating rate resulted in the overlapping of the hemicellulose and cellulose degradation events for all of the biomass samples that were studied. This observation was confirmed by the temperature values associated with the maximum point of degradation, shown in Table 7.

In Table $7, T_{\mathrm{H}}, T_{\mathrm{c}}$, and $T_{\mathrm{L}}$ are the peak temperatures of hemicellulose, cellulose, and lignin, respectively. Table 7 shows that, for the coconut and corn biomass samples, the difference between the $T_{\mathrm{H}}$ and $T_{\mathrm{C}}$ values decreased as the $\beta$-value increased. As for the rice biomass sample, there was no apparent difference in the $T_{\mathrm{H}}$ and $T_{\mathrm{C}}$ values as the $\beta$-value increased. 
Table 7. Peak Temperatures of Each Main Component of Biomass at Different Heating Rates

\begin{tabular}{|c|c|c|c|c|}
\hline Sample & $\boldsymbol{\beta}(\mathbf{K} / \mathbf{m i n})$ & $\boldsymbol{T}_{\mathbf{H}}(\mathbf{K})$ & $\boldsymbol{T}_{\mathbf{C}}(\mathbf{K})$ & $\boldsymbol{T}_{\mathbf{L}}(\mathbf{K})$ \\
\hline \multirow{3}{*}{ Rice } & 10 & 580 & 639 & 718 \\
\cline { 2 - 5 } & 20 & 593 & 630 & 726 \\
\cline { 2 - 5 } & 30 & 599 & 675 & 756 \\
\hline \multirow{3}{*}{ Coconut } & 10 & 553 & 609 & 699 \\
\cline { 2 - 5 } & 20 & 567 & 626 & 713 \\
\cline { 2 - 5 } & 30 & 578 & 621 & 725 \\
\hline \multirow{3}{*}{ Corn } & 10 & 555 & 667 & 740 \\
\cline { 2 - 5 } & 20 & 567 & 666 & 756 \\
\cline { 2 - 5 } & 30 & 654 & 761 \\
\hline
\end{tabular}

The oxidative degradation for the hemicellulose and the cellulose occurred at lower temperatures compared to the lignin (Table 7). This was because their structures were amorphous, more random, and softer. These differences lead to different reactivities, so the activation energy required to carry out the combustion of these organic polymers was lower (Carrier et al. 2011; Ren et al. 2018). This means that the activation energy values increased in the order of hemicellulose, cellulose, and lignin.

The results of the activation energy for the decomposition of biomass reported in the literature suggest that there is a tendency to increase this parameter as the heating rate increases (Melgar et al. 2008; Arango-Muñoz et al. 2015). However, the results of this study suggest that the activation energy values for each set of reactions were similar between the speeds $(\beta)$. As can be seen in Tables 4,5 , and 6 , there was no noticeable difference in the activation energies. Yao et al. (2008) found that, in the thermal decomposition of natural fibers, such energy does not show remarkable variations, or it varies shortly after the process starts.

Thermogravimetric parameters deduced from the curves obtained from the combustion of the different biomasses are shown in Table 8.

Table 8. Peak Temperatures of Each Main Component of Biomass at Different Heating Rates

\begin{tabular}{|l|l|l|l|l|l|l|}
\hline Sample & $\boldsymbol{\beta}(\mathbf{K} / \mathbf{m i n})$ & $\boldsymbol{T}_{\mathbf{0}}(\mathbf{K})$ & $\boldsymbol{T}_{\mathbf{f}}(\mathbf{K})$ & $\mathbf{M R}(\%)$ & $\mathbf{d a} / \mathbf{d} \boldsymbol{t}\left(\mathbf{s}^{-1}\right)$ \\
\hline \multirow{3}{*}{ Rice Husk } & 10 & 522 & 752 & 22.75 & 0.00174 \\
\cline { 2 - 6 } & 20 & 530 & 776 & 28.65 & 0.00423 \\
\hline \multirow{3}{*}{ Coconut Husk } & 30 & 535 & 798 & 27.51 & 0.00601 \\
\cline { 2 - 6 } & & 512 & 714 & 0.00 & 0.00190 \\
\cline { 2 - 6 } & & 522 & 739 & 0.00 & 0.00442 \\
\hline \multirow{3}{*}{ Corn Husk } & 20 & 530 & 766 & 0.00 & 0.00677 \\
\cline { 2 - 6 } & 30 & 507 & 759 & 5.70 & 0.00195 \\
\cline { 2 - 6 } & 10 & 513 & 789 & 5.05 & 0.00438 \\
\hline & 20 & 519 & 805 & 3.99 & 0.00688 \\
\hline
\end{tabular}

Characteristic temperatures: $T_{0}$ (initial temperature), and $T_{\mathrm{f}}$ (final temperature),

Residual mass after reaction (RM)

Maximum conversion speed (da/dt). 
The $T_{0}$ values did not represent significant differences between biomasses, but it is notable that the $T_{f}$ values for the coconut husk samples were lower compared to the corn husk samples and in turn with the rice husk samples.

The temperatures of maximum mass losses, for the first event, follow a tendency to increase directly with the increase in the heating rate; this behavior is not evident for the samples in the second event or reaction zone. In general terms, the coconut husk samples are those with the lowest peak temperature for this last event. Regarding the values of maximum conversion speed, for the three biomasses, values are close and follow the trend to increase with the increase in the heating rate. Similar maximum temperatures, reaction intervals and thermal profiles have also been observed in the literature (Kok and Ozgur 2017).

Of the biomasses studied, residual mass or ash values were higher for rice husk biomass (within the range 22 to $29 \%$ ), followed by samples of corn husk, the ash content of which was between 5 and $6 \%$; coconut husk samples did not leave any residue after oxidation. These values are related to the results obtained in the characterization of each biomass found through proximate analysis.

Results of the characterization showed that for biomasses the main component is holocellulose. In particular, the rice husk showed a high ash content $(22.37 \%)$, which has as a consequence a considerable decrease in its calorific power when compared to the other two biomasses studied. The highest calorific value was presented by the coconut husk with a value of $24.29 \mathrm{MJ} / \mathrm{kg}$, which makes it very attractive for its direct use in energy processes.

\section{CONCLUSIONS}

1. The results show that the biomass thermal degradation process is made up of the combustion of hemicellulose, cellulose, and lignin. Model kinetic parameters (DAEM) indicated that the activation energy distribution for the pseudocomponents follows the order of: $E_{03}($ lignin $)>E_{02}($ cellulose $)>E_{01}$ (hemicellulose).

2. The activation energy values for each set of reactions were similar between the heating rates. For all the biomass samples, the increased heating rate resulted in the overlapping hemicellulose and cellulose degradation events.

\section{ACKNOWLEDGMENTS}

The authors are grateful for the support of the vice-rectory for research, extension and social projection of the Universidad del Atlántico, Colombia, Grant call for degree projects.

\section{REFERENCES CITED}

Arango-Muñoz, M., Arenas-Castiblanco, E., and Cortés-Correa, F. (2015).

"Determinación de parámetros cinéticos para la pirólisis rápida de aserrín de pino pátula [Determination of kinetic parameters for the rapid pyrolysis of paddle pine sawdust]," Boletín del Grupo Español del Carbón 38, 9-11. 
ASTM D 3173. (2017). "Standard test method for moisture in the analysis sample of coal and coke," American Society for Testing and Materials, West Conshohocken, PA.

ASTM D 3174. (2002). "Standard test method for ash in the analysis sample of coal and coke from coal," American Society for Testing and Materials, West Conshohocken, PA.

ASTM D 3175. (2017). "Standard test method for volatile matter in the analysis sample of coal and coke," American Society for Testing and Materials, West Conshohocken, PA.

ASTM D 4239. (2017). "Standard test method for sulfur in the analysis sample of coal and coke using high-temperature tube furnace combustion," American Society for Testing and Materials, West Conshohocken, PA.

ASTM D 5373. (2016). "Standard test methods for determination of carbon, hydrogen and nitrogen in analysis samples of coal and carbon in analysis samples of coal and coke," American Society for Testing and Materials, West Conshohocken, PA.

ASTM D 5865. (2013). "Standard test method for gross calorific value of coal and coke," American Society for Testing and Materials, West Conshohocken, PA.

Bhavanam, A., and Sastry, R. C. (2015). "Kinetic study of solid waste pyrolysis using distributed activation energy model," Bioresource Technology 178, 126-131. DOI: 10.1016/j.biortech.2014.10.028

Carrier, M., Loppinet-Serani, A., Denux, D., Lasnier, J.-M., Ham-Pichavant, F., Cansell, F., and Aymonier, C. (2011). "Thermogravimetric analysis as a new method to determine the lignocellulosic composition of biomass," Biomass and Bioenergy 35(1), 298-307. DOI: 10.1016/j.biombioe.2010.08.067

Demirbaş, A. (2001). "Biomass resource facilities and biomass conversion processing for fuels and chemicals," Energy Conversion and Management 42(11), 1357-1378. DOI: 10.1016/S0196-8904(00)00137-0

Donskoi, E., and McElwain, D. L. S. (2000). "Optimization of coal pyrolysis modeling," Combustion and Flame 122(3) 359-367. DOI: 10.1016/S0010-2180(00)00115-2

Flores, J. J. A., and Quiñones, J. G. R. (2018). "Study of kinetics in thermogravimetric processes of lignocellulosic materials," Maderas: Ciencia y Tecnología 20(2) 221238. DOI: $10.4067 / \mathrm{S} 0718-221 \mathrm{X} 2018005002601$

Halim, N. A. A., Ngadi, N., Ibrahim, M. N. M., and Ansari, S. M. (2016). "Monomeric structure characterization of different sources biomass lignin," Key Engineering Materials 700, 42-49. DOI: 10.4028/www.scientific.net/KEM.700.42

Hu, M., Chen, Z., Wang, S., Guo, D., Ma, C., Zhou, Y., Chen, J., Laghari, M., Fazal, S., Xiao, B. (2016). "Thermogravimetric kinetics of lignocellulosic biomass slow pyrolysis using distributed activation energy model, Fraser-Suzuki deconvolution, and iso-conversional method," Energy Conversion and Management 118, 1-11. DOI: 10.1016/j.enconman.2016.03.058

Kok, M. V., and Ozgur, E. (2017). "Characterization of lignocellulose biomass and model compounds by thermogravimetry," Energy Sources, Part A: Recovery, Utilization, and Environmental Effects 39(2), 134-139. DOI: 10.1080/15567036.2016.1214643

Marafon, A. C., Amaral, A. F. C., and de Lemos, E. E. P. (2019). "Characterization of bamboo species and other biomasses with potential for thermal energy generation;" Pesquisa Agropecuária Tropical 49, 1-5. DOI: 10.1590/1983-40632019v4955282 
Lozano, S.-M. (2009). Evaluación de la Biomasa Como Recurso Energético Renovable en Cataluña [Evaluation of Biomass as a Renewable Resource in Catalonia], Ph.D. Dissertation, University of Girona, Catalonia, Spain.

Melgar, A., Borge, D., and Pérez, J. F. (2008). "Kinetic study of the lignocellulosic biomass devolatilization process by thermogravimetric analysis for particles sizes from 2 to 19 mm," DYNA 75(155), 123-131.

Mlonka-Mędrala, A., Magdziarz, A., Dziok, T., Sieradzka, M., and Nowak, W. (2019). "Laboratory studies on the influence of biomass particle size on pyrolysis and combustion using TG GC/MS," Fuel 252, 635-645. DOI: 10.1016/j.fuel.2019.04.091

Ninduangdee, P., and Kuprianov, V. I. (2014). "Combustion of palm kernel shell in a fluidized bed: Optimization of biomass particle size and operating conditions," Energy Conversion and Management 85, 800-808. DOI: 10.1016/j.enconman.2014.01.054

Ona, T., Sonoda, T., Shibata, M., and Fukazawa, K. (1995). "Small-scale method to determine the content of wood components from multiple eucalypt samples," TAPPI Journal 78(3), 121-126.

Oliveros, A. L. S., Muñoz, E. O., Ariza, I. E. P., Barazza, C. S. K., and Arietta, A. R. A. (2019). "Estudio TG-MS de la gasificación del carbonizado de la cáscara de Copoazú (Theobroma glandiflorum) [TG-MS study of the gasification of the carbonized shell of Copoazú (Theobroma glandiflorum)]," INGE CUC 15(1), 25-35. DOI: 10.17981/ingecuc.15.1.2019.03

Rambo, M. K. D., Schmidt, F. L., and Ferreira, M. M. C. (2015). "Analysis of the lignocellulosic components of biomass residues for biorefinery opportunities," Talanta 144, 696-703. DOI: 10.1016/j.talanta.2015.06.045

Raveendran, K., and Ganesh, A. (1996). "Heating value of biomass and biomass pyrolysis products," Fuel 75(15), 1715-1720. DOI: 10.1016/S0016-2361(96)00158-5

Ren, X., Chen, J., Li, G., Wang, Y., Lang, X., and Fan, S. (2018). “Thermal oxidative degradation kinetics of agricultural residues using distributed activation energy model and global kinetic model," Bioresource Technology 261, 403-411. DOI:

10.1016/j.biortech.2018.04.047

Santander Oliveros, A., Ortiz Muñoz E., Piñeres Ariza I., Ariza Barraza C., and Albis Arrieta A. (2019), "Estudio TG-MS de la gasificación del carbonizado de la cáscara de Copoazú (Theobroma glandiflorum)," Inge. Cuc. 15(1), 25-35. DOI: https://doi.org/10.17981/ingecuc.15.1.2019.03

Sher, F., Iqbal, S. Z., Liu, H., Imran, M., and Snape, C. E. (2020). "Thermal and kinetic analysis of diverse biomass fuels under different reaction environment: A way forward to renewable energy sources," Energy Conversion and Management 203, 112266. DOI: 10.1016/j.enconman.2019.112266

Song, C., Hu, H., Zhu, S., Wang, G., and Chen, G. (2004). "Nonisothermal catalytic liquefaction of corn stalk in subcritical and supercritical water," Energy \& Fuels 18(1), 90-96. DOI: 10.1021/ef0300141

Várhegyi, G. (2007). “Aims and methods in non-isothermal reaction kinetics," Journal of Analytical and Applied Pyrolysis 79(1-2), 278-288. DOI: 10.1016/j.jaap.2007.01.007

Várhegyi, G., Szabó, P., and Antal, M. J. (2002). "Kinetics of charcoal devolatilization," Energy \& Fuels 16(3), 724-731. DOI: 10.1021/ef010227v

Wilk, M., Magdziarz, A., Jayaraman, K., Szymańska-Chargot, M., and Gökalp, I. (2019). "Hydrothermal carbonization characteristics of sewage sludge and lignocellulosic 
biomass. A comparative study,” Biomass and Bioenergy 120, 166-175. DOI: 10.1016/j.biombioe.2018.11.016

Xiao, B., Sun, X.-F., and Sun, R.-C. (2001). "Chemical, structural, and thermal characterizations of alkali-soluble lignins and hemicelluloses, and cellulose from maize stems, rye straw, and rice straw," Polymer Degradation and Stability 74(2), 307-319. DOI: 10.1016/S0141-3910(01)00163-X

Yaman, S. (2004). "Pyrolysis of biomass to produce fuels and chemical feedstocks," Energy Conversion and Management 45(5), 651-671. DOI: 10.1016/S01968904(03)00177-8

Yao, F., Wu, Q., Lei, Y., Guo, W., and Xu, Y. (2008). "Thermal decomposition kinetics of natural fibers: Activation energy with dynamic thermogravimetric analysis," Polymer Degradation and Stability 93(1), 90-98. DOI: 10.1016/j.polymdegradstab.2007.10.012

Article submitted: October 8, 2020; Peer review completed: November 15, 2020; Revised version received and accepted: February 22, 2021; Published: March 1, 2021.

DOI: 10.15376/biores.16.2.2891-2905 